\title{
Multi-center phase II trial of chemo-radiotherapy with 5-fluorouracil, leucovorin and oxaliplatin in locally advanced esophageal cancer
}

\author{
Vanna Chiarion-Sileni · Roberto Innocente $\cdot$ Raffaele Cavina $\cdot$ Alberto Ruol $\cdot$ \\ Luigi Corti · Jacopo Pigozzo · Paola Del Bianco · Uberto Fumagalli • \\ Armando Santoro · Ermanno Ancona
}

Received: 18 June 2008 / Accepted: 8 September 2008 / Published online: 30 September 2008

(c) The Author(s) 2008. This article is published with open access at Springerlink.com

\begin{abstract}
Purpose The aim of this study was to evaluate the activity and safety of oxaliplatin/5-fluorouracil-based chemo-radiotherapy in patients with not radically resectable locally advanced esophageal cancer.

Methods Fifty-nine patients with adeno or squamous-cell carcinoma received oxaliplatin $\left(60 \mathrm{mg} / \mathrm{m}^{2}\right)$, and leucovorin $\left(20 \mathrm{mg} / \mathrm{m}^{2}\right.$ on days $\left.1,8,15,29,36,43,50,57\right)$ followed by continuous infusion fluorouracil $\left(200 \mathrm{mg} / \mathrm{m}^{2}\right.$ per day on days 1-22 and 29-64) with radiotherapy (1.8 Gy daily fractions to a total dose of $45 \mathrm{~Gy}$, from days 29 to 64). When feasible, surgery was scheduled 6-8 weeks after chemoradiotherapy completion. The primary endpoint was 1-year progression-free survival.

Results Forty (68\%) patients completed treatment without modifications. An objective clinical response was seen in

Presented in part at the 41st annual meeting of the American Society of Clinical Oncology, Orlando, FL, USA, May 13-17, 2005, the 107th Annual Meeting of the Italian Surgery Society, Cagliari, Italy, October 9-12, 2005 and the 17th ICACT Meeting, Paris, France, January 30February 2, 2006.
\end{abstract}

V. Chiarion-Sileni $(\bowtie) \cdot J$. Pigozzo

Medical Oncology Unit, Istituto Oncologico Veneto-IRCCS,

Via Gattamelata, 6435128 Padova, Italy

e-mail:mgaliz@tiscali.it

\section{R. Innocente}

Department of Radiation Oncology,

C.R.O.-National Cancer Institute, Aviano, Italy

R. Cavina $\cdot$ A. Santoro

Department of Medical Oncology and Hematology,

Istituto Clinico Humanitas, Rozzano, Milan, Italy

A. Ruol

Department of Gastroenterological and Surgical Sciences,

Clinica Chirurgica III, University of Padova, Padova, Italy
35 patients (59\%). Esophagectomy was possible in 33 patients and a complete resection (R0) was achieved in 26 (79\%) with 6 pathologic complete responses (pCR) and 3 near pCR.

At a median follow-up of 39.7 months for the surviving patients, the median progression-free and overall survivals were 11 months (95\% CI 6.5-14) and 18.5 months (95\% CI 13-29). The 1-year progression-free and overall survivals were $47.5 \%$ (95\% CI 34-59.5\%) and 63\% (95\% CI 49$74 \%)$. Major toxicities were esophagitis (20\% G3 and 5\% G4) and diarrhea (8.5\% G3 and $8.5 \%$ G4). Hematological toxicity (7\% G3 and 3\% G4) was less common; severe neurotoxicity (3\% G3) was infrequent.

Conclusions Concurrent oxaliplatin, leucovorin, fluorouracil and radiotherapy followed or not by esophagectomy has a tolerable toxicity and promising activity in locally advanced esophageal cancer.

Keywords Phase II study · Oxaliplatin · Esophageal cancer · Chemo-radiotherapy
L. Corti
Department of Radiotherapy,
Istituto Oncologico Veneto-IRCCS, Padova, Italy
P. Del Bianco
Clinical Trials and Biostatistics Unit,
Istituto Oncologico Veneto-IRCCS, Padova, Italy
U. Fumagalli
Department of Surgery, Istituto Clinico Humanitas,
Rozzano, Milan, Italy
E. Ancona
Istituto Oncologico Veneto-IRCCS, Padova, Italy 


\section{Introduction}

Esophageal carcinoma is a highly aggressive neoplasm with long-term survival rates below $20 \%$. The lethality of this disease is a consequence of advanced disease stage at diagnosis combined with dysphagia, weight loss and co-morbid conditions, related to alcohol and tobacco abuse [13].

Surgery is still considered to be the standard treatment for patients who are medically fit and in whom a complete resection can be achieved [24], while chemo-radiotherapy is the standard treatment for patients with locally advanced disease or medically unfit for surgery [12, 21, 29]. Nevertheless, neither approach is particularly effective with locoregional failure and distant metastasis, both common after either treatment. More recently squamous cell cancer and adenocarcinoma of the esophagus have been recognized as two distinct entities with differences in pathogenesis, epidemiology, tumor biology and prognosis [35]. A recent metaanalysis evidenced a significant survival benefit with preoperative chemo-radiotherapy in both histological tumor types [18], while preoperative chemotherapy was effective to a lesser extent only in adenocarcinoma. To date, randomized trials on squamous cell carcinoma, have not demonstrated any benefit on survival. The significant postoperative mortality might have affected the possible therapeutic benefit; however, surgical resection had a substantial improvement in local control and decreased the need for stent placement $[6,37]$.

Four cycles of fluorouracil/cisplatin, with radiotherapy ( $50.4 \mathrm{~Gy} / 5$ weeks), is the standard regimen for locally advanced patients, but relevant toxicity prevented the full administration of chemotherapy in $46 \%$ of patients and caused acute life-threatening toxic effects in $20 \%$ [12, 21]. Moreover, when cisplatin-based chemo-radiotherapy was followed by surgery, postoperative mortality increased in some studies to $12 \%$ [38].

Oxaliplatin (trans-1-1,2-diaminocyclohexane oxaliplatinum), a novel anti-neoplastic platinum analog, has been safely and effectively combined with fluorouracil/leucovorin, in the treatment of colon and rectal cancer $[15,16]$. In advanced esophagogastric cancer, oxaliplatin, combined with fluorouracil and epirubicin or epirubicin and capecitabine, in a phase III study, was as effective as the cisplatin combination and associated with less neutropenia, renal toxicity and alopecia [14]; and in combination with fluorouracil and leucovorin was more effective than a cisplatinbased combination in patients older than 65 years [2].

Pre-clinical studies have also shown that oxaliplatin is a potent radio-sensitizing agent [7].

The efficacy and safety of combining oxaliplatin/fluorouracil and radiation were first established in phase I and II studies in rectal cancer [9, 17], and esophageal cancer [25]. In advanced (T3 and T4) esophageal cancer, a complete clearance of tumor cells is more difficult to obtain [34]. A weekly schedule, which should optimize the inhibition of sub-lethal radiation-induced DNA damage repair [4, 11], might increase the pathological complete response (pCR) rate through greater tumor shrinkage. In a phase I study, our group demonstrated that oxaliplatin, given weekly in combination with full-dose infusional FU and RT, is an active regimen in advanced rectal cancer [4]. The favorable toxicity profile of this regimen, reflected in the high treatment compliance, the full dose of radiation delivered and the low surgical morbidity, prompted us to test this combination in locally advanced esophageal cancer (LAEC) patients.

On the basis of these data, we planned this study to assess the efficacy and safety of oxaliplatin/leucovorin/fluorouracil (FLOX) and radiotherapy in a multi-institutional phase II trial, in patients with LAEC.

The primary end-point of this study was to evaluate the efficacy of this combination in both histologies. Dealing with LAEC patients where the evaluation of clinical response is difficult and the pathological response is valuable only in resected patients, we chose the 1-year progression-free survival (PFS) as a measure of efficacy. PFS is less controversial than the response rate and can be applied to all patients, even those who do not become operable, decline surgery, or die before evaluation.

Secondary endpoints included overall survival (OS), toxicity, response, $\mathrm{pCR}$ and complete resection rates, surgical morbidity and mortality.

\section{Patients and methods}

Patients aged less than 75 years, with an ECOG performance status $\leq 2$, a histologically confirmed diagnosis of LAEC, a squamous cell carcinoma or adenocarcinoma, and the American Joint Committee on Cancer [20] Stages IIBIVA, not radically resectable, were eligible. The criteria for unresectability were defined as follows: adherence to the aorta of more then $90^{\circ}$; invasion of the tracheo-bronchial tree, azygos vein, recurrent nerve; M1a nodal metastases, cervical esophagus involvement. Patients with $\mathrm{T}$ lesions less than T4 in the presence of extensive nodal involvement were also included. Criteria for non-operability were cirrhosis (any stage) associated with portal vein hypertension, respiratory failure, and heart failure (New York Heart Association classes III-IV). Further requirements for eligibility included an initial absolute neutrophil count $\geq 2 \times 10^{9} / 1$; platelet count $\geq 150 \times 10^{9} / 1$; adequate hepatic (AST and ALT <two times normal, bilirubin level $<20 \mathrm{mmol} / \mathrm{l}$ ) and renal (serum creatinine level $<150 \mu \mathrm{mol} / \mathrm{l}$ ) function. Patients were excluded due to the following: $\geq$ grade 2 neuropathy, tracheal-esophageal fistula, severe co-morbid conditions, active infections. 
Pre-treatment evaluation

Before entering the study, all patients were evaluated by a multidisciplinary team, which included a medical oncologist, a radiotherapist, a surgeon and a gastroenterologist, and were required to give a written informed consent.

Pre-treatment evaluation included physical examination, complete blood cell count and serum chemistry tests; barium esophagram; upper gastro-esophageal endoscopy, bronchoscopy (in upper and middle third tumors); endoscopic ultrasound (EUS); chest and abdominal helical CT scan, and cervical ultrasound with fine-needle aspiration biopsy of suspicious nodes.

Patients were staged according to the results of the EUS and CT scan. In the case of a discrepancy between the EUS and CT scan findings, the patient was classified according to the worst stage both for $\mathrm{T}$ and $\mathrm{N}$.

Dysphagia was scored from 0 to 4 using a standard five point scale [26].

The ethical committee of each participating center approved both the protocol and informed consent.

\section{Treatment}

\section{Chemotherapy}

Three weekly induction doses of FLOX followed by five doses with concurrent radiotherapy were delivered in an outpatient setting through a central venous access.

Briefly, oxaliplatin was administered as a 2-h infusion on days $1,8,15,29,37,43,50,57$ at a dose of $60 \mathrm{mg} / \mathrm{m}^{2}$, as previously established in our single-center phase I study, on rectal cancer [4], and was followed by leucovorin $20 \mathrm{mg} / \mathrm{m}^{2}$ over $10^{\prime}$ and a continuous infusion of fluorouracil $200 \mathrm{mg} /$ $\mathrm{m}^{2}$ per day over days 1-22 and 29-64.

Patients received the planned treatment with no dose reduction if they had a neutrophil count $\geq 1,500 \mu \mathrm{l}^{-1}$ and a platelet count $\geq 100,000 \mu \mathrm{l}^{-1}$; otherwise chemotherapy was delayed until complete toxicity recovery. Treatment modifications were specified for hematological, gastrointestinal and neurological toxicity using the NCI Common Toxicity Criteria version 2.0.

Oxaliplatin and fluorouracil were reduced to $75 \%$ of the initial dose if any of the following events occurred: neutrophil count $<1,000 \mu \mathrm{l}^{-1}$, platelet count $<50,000 \mu \mathrm{l}^{-1}$, or grades 3-4 non-hematological toxicity. In the case of neutrophil count $<500$, fever or platelet count $<10,000 \mu \mathrm{l}^{-1}$, oxaliplatin and fluorouracil doses were reduced to $60 \%$ of the initial dose. The oxaliplatin dose alone was reduced to 75 or $60 \%$ of the initial dose in the case of grades 2 or 3 neurotoxicity, respectively, in the case of grade 4 , the dose was withheld.

\section{Radiotherapy}

Radiotherapy was delivered at $45 \mathrm{~Gy}$ in 25 fractions over 5 weeks, using a high-energy linear accelerator with a threedimensional multi-field technique, with a CT simulation, from day 29 of chemotherapy treatment. The planned target volume for carcinoma of the upper or middle third esophagus included the primary tumor with $5 \mathrm{~cm}$ longitudinal margins, metastatic nodes with a $2 \mathrm{~cm}$ margin, supraclavicular fossa and mediastinum. For carcinoma of the lower third esophagus, the field was extended to include both the perigastric and celiac nodes. This involved an initial phase using anteroposterior/posteroanterior fields to a dose of $30.6 \mathrm{~Gy}$ in $1.8 \mathrm{~Gy}$ fractions. The radiation portals were then changed to encompass the primary tumor and metastatic nodes with a 2$\mathrm{cm}$ margin, using off-cord conformal oblique fields up to a dose of $45 \mathrm{~Gy}$. In patients with cervical esophageal tumor, the radiotherapy dose was increased up to $60 \mathrm{~Gy}$.

In the case of grade 3 or 4 mucositis or diarrhea, radiotherapy was withdrawn till recovery.

\section{Surgery}

Patients were restaged 4-6 weeks after completion of chemo-radiotherapy, repeating the pre-treatment staging work-up. Medically fit patients, whose tumors became radically resectable, were offered an Ivor-Lewis esophagectomy performed 6-8 weeks after chemo-radiation. Resection of the esophagus and the proximal stomach was performed through a separate right thoracic and middle abdominal approach. Resection included excision of the para-esophageal, intra-carenal, paracardial, left gastric, and celiac lymph nodes (two-field lymphadenectomy). The resected esophagus was usually replaced by the stomach using a cervical or intra-thoracic esophagus-gastric anastomosis, depending on the level of tumor location.

\section{Assessment of response}

Assessment of clinical response to protocol therapy was performed 4 weeks after the end of hemo-radiotherapy according to WHO criteria. In resected patients, a pCR was defined as the absence of viable tumor cells detected in the primary tumor and the lymph nodes (pT0 pN0).

For patients who could not proceed to surgery, the clinical CR was defined as the absence of any residual tumor at CT scan, endoscopy, EUS, biopsy, confirmed by a new endoscopy with biopsy and a PET-CT scan 3 months later.

\section{Follow-up}

Follow-up included a multidisciplinary visit every 3 months up to 2 years and every 6 months thereafter. 
Each visit included physical examination, complete blood count, and chemistry panel; chest, abdomen and pelvic CT and endoscopy with biopsy were performed every 6 months.

\section{Statistical considerations}

Using a single-stage design according to Fleming, a 25\% 1year PFS or less was considered to be insufficient to warrant further investigation. On the other hand, a probability of PFS $>43 \%$ would be clinically sufficient and indicates that further investigation of this regimen is appropriate. This level of efficacy was chosen according to our experience with $5 \mathrm{FU} /$ cisplatin/RT and considering the literature data of efficacy in patients with stage III and IVa LAEC.

With a sample size of 58 patients, the risk of erroneously recommending a treatment whose PFS is inadequate amounts to $5 \%$ while the chance of erroneously rejecting the treatment is less than $15 \%$ in case of truly promising activity set to $43 \%$ PFS.

All analyses were based on the intent-to-treat population.

The PFS time was calculated from the beginning of chemotherapy to the date of progressive disease, death or last follow-up. The Kaplan-Meier method was used to estimate the survival curve.

Actual dose intensity was calculated as recommended by Hryniuk [22].

Analyses were performed using the SAS statistical package (SAS, release 9.1.3, Cary, NC, USA).

\section{Results}

A total of 59 patients were enrolled between November 2002 and June 2005. Patients' characteristics are presented in Table 1. Fifty-five patients (93\%) had node metastases (N1: 50, M1a: 5). All 59 enrolled patients were evaluated for safety, PFS and OS. Figure 1 shows the progress of all patients during the trial.

Compliance with the regimen and toxicity

\section{Chemo-radiotherapy}

Forty patients (68\%) completed the eight planned FLOX chemotherapy doses, without any modifications. The reasons for not completing all chemotherapy were toxicity $(\mathrm{n}=17)$, progressive disease $(n=1)$ and refusal $(n=1)$. The mean relative dose intensity of oxaliplatin and fluorouracil were 0.9 and 0.9 (induction phase) and 0.8 and 0.8 (concurrent phase), respectively (Fig. 2). Fifty-seven patients started the concurrent phase of the treatment: 49
Table 1 Baseline characteristics

\begin{tabular}{|c|c|c|}
\hline & No. of patients & $\%$ \\
\hline \multicolumn{3}{|l|}{ Age, years } \\
\hline Median (range) & $60(41-74)$ & \\
\hline \multicolumn{3}{|l|}{ Gender } \\
\hline Female & 11 & 19 \\
\hline Male & 48 & 81 \\
\hline \multicolumn{3}{|c|}{ ECOG performance status } \\
\hline 0 & 16 & 27 \\
\hline 1 & 43 & 73 \\
\hline \multicolumn{3}{|l|}{ Dysphonia } \\
\hline No & 56 & 95 \\
\hline Yes & 3 & 5 \\
\hline Weight loss $>10 \%$ & 17 & 29 \\
\hline \multicolumn{3}{|l|}{ Histology } \\
\hline Adenocarcinoma & 8 & 13 \\
\hline Squamous & 50 & 85 \\
\hline Undifferentiated & 1 & 2 \\
\hline \multicolumn{3}{|l|}{ Anatomic site } \\
\hline Cervical & 4 & 7 \\
\hline Upper/mid thoracic & 35 & 59 \\
\hline Lower thoracic & 20 & 34 \\
\hline \multicolumn{3}{|l|}{ TNM stage } \\
\hline T1N1M0 & 1 & 1.7 \\
\hline T2N1M0 & 2 & 3.4 \\
\hline T3N1/NxM0 & 41 & 69.5 \\
\hline T4/M0 any $\mathrm{N}$ & 10 & 16.9 \\
\hline Any $\mathrm{T}$, any $\mathrm{N}, \mathrm{M} 1 \mathrm{~A}$ & 5 & 8.5 \\
\hline
\end{tabular}

$(83 \%)$ of them received the whole radiotherapy dose. Unplanned interruptions of more than 2 days occurred in 14 patients as a result of toxicity; 8 patients discontinued radiotherapy due to esophagitis and diarrhea after a median of 40 Gy (range 22-40).

Table 2 lists the whole incidence of toxicity during chemo-radiotherapy. Esophagitis was the most common toxicity, with grade 3 or 4 in 15 patients $(25 \%)$. Ten patients $(17 \%)$ suffered from grade 3 or 4 diarrhea. Hematological toxicity was modest with only four (7\%) and two (3\%) patients with grade 4 neutropenia and thrombocytopenia, respectively. One patient had a pulmonary edema associated with septicemia after the seventh week of treatment, with complete resolution within 7 days. Another patient had a candida pulmonary infection requiring a month of intravenous anti-micotics. There was one possible treatment-associated death: this patient who was diabetic died of aspiration pneumonia while experiencing grade 4 neutropenia and trombocytopenia. Grade 3 neuropathy was observed in three patients, five had a venous thrombosis related to the central venous catheter, and seven patients 


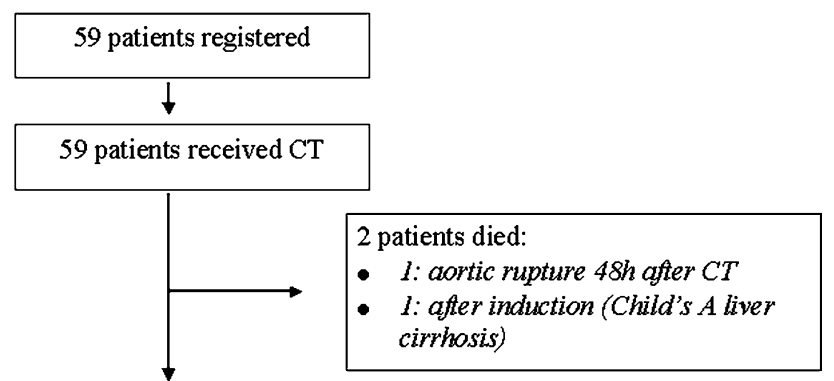

\section{7 patients received CRT}

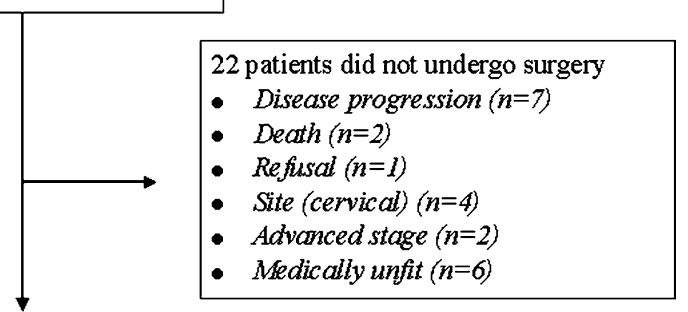

35 patients underwent surgery

Fig. 1 Trial progress. $C T$ chemotherapy, $C R T$ chemo-radiotherapy

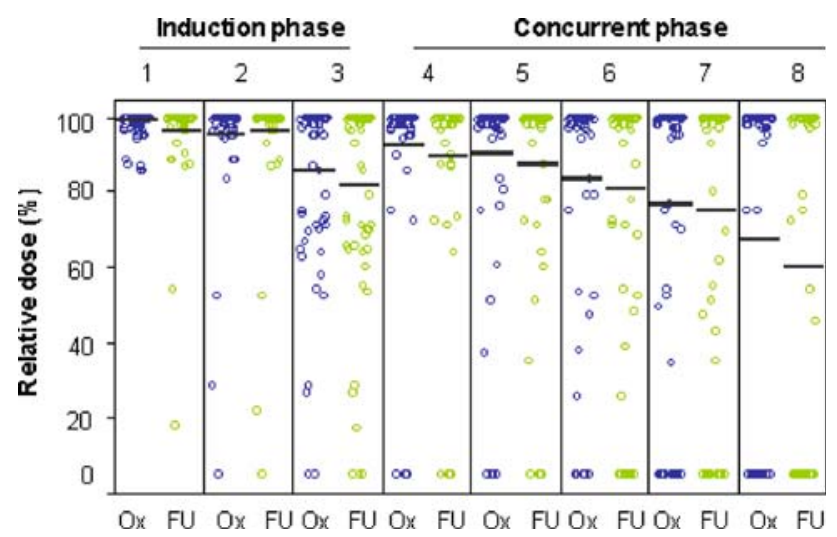

Fig. 2 Mean relative dose-intensities during each cycle of therapy. Circles plot the dose-intensity with respect to the prescribed dose of drug for each patient. Bars represent the mean relative dose-intensity. $O x$ oxaliplatin, $F U$ fluorouracil

had drug-related fever, usually occurring $48 \mathrm{~h}$ after oxaliplatin and lasting $24 \mathrm{~h}$.

Esophagectomy and two-field lymphadenectomy was performed on 33 patients ( 5 adenocarcinoma, 1 undifferentiated and 27 squamous cell) after a median interval of 6 weeks (range 3-13) from chemo-radiotherapy. Postoperative complications of any grade occurred in 10 patients (one adenocarcinoma, one undifferentiated and eight squamous cell; Table 3): of these, two (squamous cell) died of an acute respiratory distress syndrome, one (undifferentiated) had septicemia related to a venous catheter gram-positive infection.
Table 2 Treatment induced toxicity

\begin{tabular}{|c|c|c|c|c|c|c|}
\hline \multirow[t]{2}{*}{ Toxicity $^{\mathrm{a}}$} & \multicolumn{2}{|c|}{ Grades $1-2$} & \multicolumn{2}{|c|}{ Grade 3} & \multicolumn{2}{|c|}{ Grade 4} \\
\hline & $N$ & $\%$ & $N$ & $\%$ & $N$ & $\%$ \\
\hline \multicolumn{7}{|l|}{ Gastrointestinal } \\
\hline Esophagitis & 9 & 15 & 12 & 20 & 3 & 5 \\
\hline Diarrhea & 15 & 25 & 5 & 8 & 5 & 8 \\
\hline Nausea/vomiting & 32 & 54 & 2 & 3 & 2 & 3 \\
\hline \multicolumn{7}{|l|}{ Blood/bone marrow } \\
\hline Leucopoenia & 9 & 15 & 4 & 7 & 2 & 3 \\
\hline Neutropoenia & 6 & 10 & & & 4 & 7 \\
\hline Thrombocytopoenia & 8 & 14 & 2 & 3 & 2 & 3 \\
\hline Anemia & 12 & 20 & 2 & 3 & & \\
\hline Cardiac toxicity & 3 & 5 & 1 & 2 & & \\
\hline Asthenia & 13 & 22 & 4 & 7 & & \\
\hline \multicolumn{7}{|l|}{ Neurology } \\
\hline Neuropathy & 9 & 15 & 2 & 3 & & \\
\hline Numbness & 22 & 37 & 1 & 2 & & \\
\hline Infection & 2 & 3 & 1 & 2 & 2 & 3 \\
\hline Fever drug related & 6 & 10 & 1 & 2 & & \\
\hline Renal & 1 & 2 & 1 & 2 & & \\
\hline Dermatological & 7 & 12 & 1 & 2 & & \\
\hline Hepatic & 5 & 8 & & & & \\
\hline
\end{tabular}

${ }^{a}$ Worst grade/patient, 59 patients

Table 3 Surgery outcomes

\begin{tabular}{lc}
\hline & No. of patients \\
\hline Type of surgery & 26 \\
R0 resection & 7 \\
R1-2 resection & 2 \\
Exploration only & \\
Pathological response & 6 \\
ypT0N0 & 3 \\
ypT0N1 & \\
Surgical morbidity & 10 \\
Peri-operative complications & 2 \\
Death (ARDS) & 2 \\
Anastomotic leak & 1 \\
Sepsis & 2 \\
Pulmonary infection & 3 \\
Cardiac complications &
\end{tabular}

$R O$ Complete resection, $R 1$ resection with microscopic residual disease, $R 2$ resection with macroscopic residual disease

Efficacy and surgical parameters

Patients' outcome was assessed as of 1 September 2007. The median follow-up time was 18.5 months (range 0.354.7), and 39.7 months (range 26.4-54.7) for patients who 
are still alive. Thirty-five patients (59\%) had an objective response (95\% CI $46-72 \%$ ) by radiological imaging, 12 had stable disease, 8 progressed and 4 died before evaluation: two of a massive esophageal hemorrhage; one died suddenly, at home 6 days after the third week of chemotherapy; and one died of aspiration pneumonia. Objective responses were observed in 32 patients with squamous cell histology, in 2 with adenocarcinoma and in the patient with undifferentiated cell histology.

Thirty-five patients (59\%) underwent surgery. The reasons for not undergoing surgical resection are listed in Fig. 1. Table 3 summarizes surgical results. A complete resection was achieved in 26 patients. A pCR (ypTONOM0) was documented in six (17\% of resected) and three patients had complete $\mathrm{T}$ clearance with only one node containing tumor micro foci (ypT0N1M0). The pathological responses were observed in seven patients with squamous cell histology, in one with adenocarcinoma and the one with undifferentiated cell histology.

Four patients with a complete tumor regression, documented by endoscopy, biopsy, CT and PET-CT scan, who did not undergo resection, are still in complete clinical response after a median follow-up of 40 months (range 36-48).

The median and 1-year PFS were 11 months $(95 \% \mathrm{CI}$ 6.5-14) and 47.5\% (95\% CI 34-59.5), respectively. Median PFS for adenocarcinoma and squamous cell histology was 9 and 11 months, respectively.

The median OS was 18.5 months (95\% CI 13-27), 12 months for adenocarcinoma and 19 for squamous cell histology. The 1-year and 3-year OS probability was $63 \%$ (95\% CI 49-74) and 31.5\% (95\% CI 20-44), respectively (Fig. 3).

In patients with clinical response, the median OS was 26.7 months (95\% CI 18-) with 1-year and 3-year OS of $85.7 \%$ (95\% CI 69-94) and 41.9\% (95\% CI 25-58), respectively.

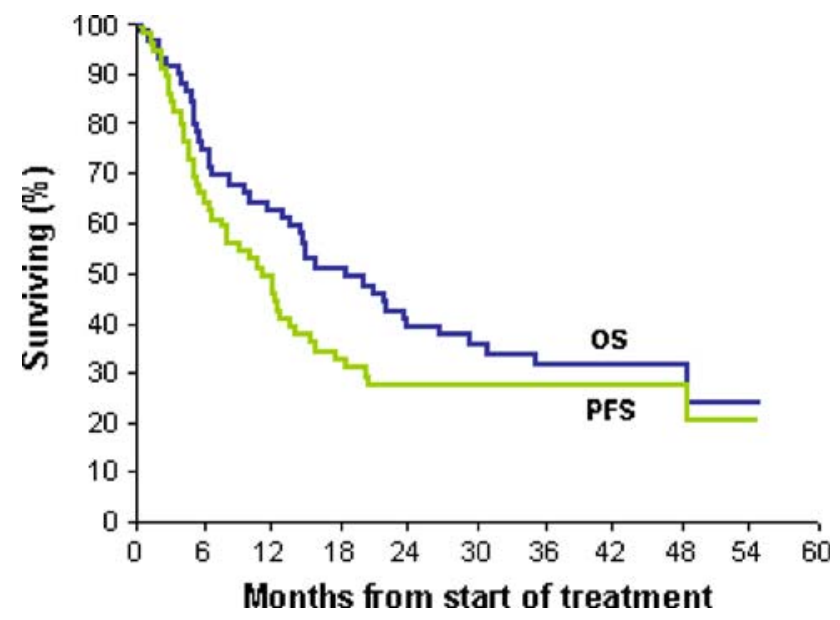

Fig. 3 Kaplan-Meier curves for progression-free survival $(P F S)$ and overall survival $(O S)$
The median OS in the 33 resected patients was 29.3 months (95\% CI 20-) with 1-year and 3-year OS of $81.8 \%$ (95\% CI 64-91) and 40.9\% (95\% CI 24-57), respectively. All patients with a pathological response were alive at a median follow-up of 39 months except one patient with ypT0N1M0 who died after 21 months from starting therapy.

\section{Site of the first occurrence}

Fifteen patients $(25 \%)$ are still without recurrence at a median follow-up of 40 months (range 26.4-54.7). The first site of recurrence was local in $12(20 \%)$ and distant in 21 $(36 \%)$.

\section{Discussion}

The treatment of patients with LAEC is challenging for many reasons: the extension and localization of the tumor at diagnosis, poor patients' conditions and the frequent presence of multiple co-morbidities, which hamper the full administration of treatments and their efficacy [36].

The activity of oxaliplatin, combined with FU or cisplatin in different schedules, with or without radiotherapy, has been recently tested and reported in EC in different studies [25, 30-32].

Khushalani et al. [25] evaluated a standard dose of $85 \mathrm{mg} / \mathrm{m}^{2}$ every 2 weeks in a mixed population of stages II, III, IVb EC, with a prevalence of adenocarcinomas (80\%). Mauer et al. [30] tested the same dose every 2 weeks, without XRT in a phase I study on 35 patients with recurrent or metastatic adeno and squamous esophageal cancer; O'Connor et al. [32] studied this schedule in combination with RT in 33 patients with adenocarcinoma and 9 with squamous carcinoma. Maurel et al. [31] combined oxaliplatin with cisplatin and 96-h FU infusion and Jatoi et al. [23] combined oxaliplatin every 3 weeks with capecitabine, in patients with metastatic esophageal adenocarcinoma and gastric cardia. All the above-mentioned authors concluded that oxaliplatin had significant anti-tumor activity and a favorable toxicity profile in patients with esophageal cancer.

Two phase III studies in advanced esophagogastric cancer have confirmed the previous phase II findings establishing that the oxaliplatin combinations were as effective as the cisplatin combinations and less toxic [2, 14].

Our study is the first to evaluate a weekly combination of oxaliplatin in previously untreated LAEC patients with a high prevalence of squamous cell histology.

Squamous and adenocarcinoma of the esophagus are now clearly recognized as different entities, not only in epidemiology, tumor location and postoperative complications, but 
also in post-treatment outcome. A higher incidence of deaths due to secondary tumors and co-morbidities was reported in squamous cell type and due to metastatic spreading in adenocarcinoma $[28,35]$. However, the low number of adenocarcinoma patients enrolled did not allow us to statically compare the two histology populations.

Twenty-five percent of patients are alive without evidence of recurrence at a median follow-up of 40 months. Considering that we treated only patients who were not radically resectable at presentation; this demonstrates the efficacy of the oxaliplatin combination. The median OS of 18.5 months and 3-year OS of 31.5 months compare favorably with the median OS of 12.5 months reported in the RTOG-085 study [12, 21]. The activity observed compares well also with the median OS of 17.7 months reported by Bedenne et al. [6] and the 16.4 months reported by Stahl et al. [37]. In our study, $87 \%$ of the patients had stage III and $8 \%$ stage IVa disease; $17 \%$ had a T4 lesion. Moreover, 93\% had nodal involvement which is the most important prognostic factor [40]. In the RTOG-085 study, nodal involvement was reported in only $13 \%$ of patients and there were no patients with T4 or M1a disease. Stahl et al. [37] study excluded patients with M1a disease and $18 \%$ of them did not have evidence of nodal metastases; Bedenne et al. [6] excluded patients with T4 and M1a lesions, and 59\% were without evidence of nodal metastases.

The activity observed with this oxaliplatin combination is also better than that obtained in a similar patient population using docetaxel in combination with cisplatin and FU, followed by carboplatin and concurrent radiotherapy, and surgery [10]. In advanced loco-regional disease, Polee et al. [33] reported 17 of the 178 patients surviving at least 3 years using different cisplatinum based combinations. Adelstein et al. [1] obtained a median OS of 15 months and a 3-year OS of 30\% in T3-4 or N1 or M1 patients, using a paclitaxel combination but reported a treatment related mortality of $18 \%$.

The overall pCR rate (17\%) we obtained, even if apparently lower than the average $24 \%$ calculated by Geh [19] in a pooled analysis of 2,704 patients, is noteworthy considering that the possibility of achieving a pCR is related to the stage [27], and that six patients with a clinical and long lasting CR did not undergo surgery. In the O'Connor [32] study, the overall pCR rate was $25 \%$; perhaps, the higher dose of radiation used in this study (50.4 Gy) contributed to increase the number of pCRs.

The radiotherapy dose is an important issue in the achievement of loco-regional control. When radiotherapy is employed as the sole therapeutic modality, there is an association between a higher dose and 5-year survival [41]. Instead, in the setting of concurrent CRT, the optimal radiation dose has not been clearly defined. Zhang et al. [41] observed that in the correlation between the radiation dose, concurrent with CT and loco-regional control, the slope of the curve flattened in the high-dose region, suggesting a threshold in tumor response, and this flattening became quite evident after a dose of 45-46 Gy. Since higher doses could increase treatment toxicity and surgical morbidity, and esophagectomy was a planned option in our study, we decided to limit the total dose to $45 \mathrm{~Gy}$, although in the four patients with tumor located in the cervical esophagus, where an esophagectomy was not planned, we proceeded to a total dose of 60 Gy without relevant toxicity.

In esophageal cancer, especially in patients with the squamous cell histology type, co-morbidities often make the delivery of treatment difficult due to related toxicity.

In the RTOG randomized study, only $54 \%$ of patients completed the four planned cycles of FU/cisplatin; side effects were severe in $44 \%$ and life-threatening in $20 \%$ and 10 patients $(8.7 \%)$ died during the treatment [21]. Some authors [8] reported up to $16 \%$ of treatment-related deaths with the same combination, even using chemotherapy alone. In a randomized study in operable patients [3], using preoperative CT alone, we were able to deliver $68 \%$ of three planned cycles of FU/cisplatin. In a similar study, Kelsen et al. [24] delivered $71 \%$ of the planned CT preoperatively, and $38 \%$ postoperatively. In the present study, despite the more advanced stage of disease, $68 \%$ of patients completed the whole treatment plan, and $88 \%$ of the cycles were administered without modifications.

The hematological toxicity of this combination was moderate, grades 3-4 occurred in less than $10 \%$ of patients, and this percentage is among the lowest reported in this setting and not superior to that reported with oxaliplatin regimens delivered without radiotherapy $[2,14]$.

Predominant toxicity was esophagitis and two-thirds of the patients who had severe esophagitis also suffered from diarrhea. The incidence of diarrhea was greater than that observed in our phase I-II study in the preoperative treatment of locally advanced rectal cancer [4]. We can argue that the combination of malnourishment, smoke and alcohol abuse may make the intestinal mucosa more sensitive to treatment damage, since gastrointestinal toxicity was more frequent in patients with a greater weight loss. When we became more aware of this risk and paid careful attention to the fluid and electrolytic balance, dehydration and related life-threatening complications ceased. All the early and toxic deaths occurred in patients with more advanced disease and squamous cell histology.

We proposed esophagectomy to all consenting patients who were judged radically resectable after chemo-radiotherapy to improve local control since a higher local failure is reported in patients with a higher $\mathrm{T}$ staging $[6,18,37]$. We avoided esophagectomy in patients with cervical involvement requiring a pharyngo-laryngectomy and in poor condition patients where the risk of post-surgical 
mortality is higher. In fact, the overall peri-operative death $(6 \%)$ and the peri-operative complication (23\%) rates were similar to those reported with surgery alone [5, 39] and did not seem to be increased by this preoperative treatment.

New protocols, combining oxaliplatin-containing regimens with target agents such as cetuximab, which inhibits the epidermal growth factor receptor (EGFR), and/or bevacizumab, which blocks the vascular endothelial growth factor (VEGF), are in progress and could increase the median survival and the still low rate of cure in EC. To this aim, we have started a multi-center phase II study testing the activity and safety of the addition of cetuximab to oxaliplatin/FU/leucovorin and radiotherapy in EC.

In conclusion, our results indicate that the oxaliplatin/ FU/leucovorin combination is active in the treatment of EC. In view of the better toxicity profile, the easier administration and the at least comparable activity, oxaliplatin could safely replace cisplatin in the treatment of this tumor.

Acknowledgments We thank the investigators at the participating institutions: R. Alfieri, G. Battaglia, P. Bocus, C. Boso, C. De Rossi, G. L. De Salvo, D. Fiore, D. Kilmartin (IOV-IRCCS, Padova); B. Ercoli, R. Rosati (ICH, Milano); I. M. Brunetti, M. Rossi (S. Chiara, Pisa); E. Galligioni, G. Pani, L. Tomio (S. Chiara, Trento). The Authors kindly thank Denise Kilmartin for editing the manuscript. This research was supported in part by the G. B. Morgagni Foundation, Italy.

\section{Conflicts of interest statement None.}

Open Access This article is distributed under the terms of the Creative Commons Attribution Noncommercial License which permits any noncommercial use, distribution, and reproduction in any medium, provided the original author(s) and source are credited.

\section{References}

1. Adelstein DJ, Rice TW, Rybicki LA, Larto MA, Ciezki J, Saxton J, DeCamp M, Vargo JJ, Dumot JA, Zuccaro G (2000) Does paclitaxel improve the chemoradiotherapy of locoregionally advanced esophageal cancer? A nonrandomized comparison with fluorouracil-based therapy. J Clin Oncol 18:2032-2039

2. Al-Batran SE, Hartmann JT, Probst S, Schmalenberg H, Hollerbach S, Hofheinz R, Rethwisch V, Seipelt G, Homann N, Wilhelm G, Schuch G, Stoehlmacher J, Derigs HG, Hegewisch-Becker S, Grossmann J, Pauligk C, Atmaca A, Bokemeyer C, Knuth A, Jager E (2008) Phase III trial in metastatic gastroesophageal adenocarcinoma with fluorouracil, leucovorin plus either oxaliplatin or cisplatin: a study of the Arbeitsgemeinschaft Internistische Onkologie. J Clin Oncol 26:1435-1442

3. Ancona E, Ruol A, Santi S, Merigliano S, Sileni VC, Koussis H, Zaninotto G, Bonavina L, Peracchia A (2001) Only pathologic complete response to neoadjuvant chemotherapy improves significantly the long term survival of patients with resectable esophagal squamous cell carcinoma: final report of a randomized, controlled trial of preoperative chemotherapy versus surgery alone. Cancer 91:2165-2174

4. Aschele C, Friso ML, Pucciarelli S, Lonardi S, Sartor L, Fabris G, Urso ED, Del Bianco P, Sotti G, Lise M, Monfardini S (2005) A phase I-II study of weekly oxaliplatin, 5-fluorouracil continuous infusion and preoperative radiotherapy in locally advanced rectal cancer. Ann Oncol 16:1140-1146

5. Bailey SH, Bull DA, Harpole DH, Rentz JJ, Neumayer LA, Pappas TN, Daley J, Henderson WG, Krasnicka B, Khuri SF (2003) Outcomes after esophagectomy: a ten-year prospective cohort. Ann Thorac Surg 75:217-222 Discussion 222

6. Bedenne L, Michel P, Bouche O, Milan C, Mariette C, Conroy T, Pezet D, Roullet B, Seitz JF, Herr JP, Paillot B, Arveux P, Bonnetain F, Binquet C (2007) Chemoradiation followed by surgery compared with chemoradiation alone in squamous cancer of the esophagus: FFCD 9102. J Clin Oncol 25:1160-1168

7. Blackstock A, Hess S, Chancy S, Tepper J (1999) Oxaliplatin: in vitro evidence of its radiation sensitizing activity: pre-clinical observations relevant to clinical trials. Abstract 202. Int J Radiat Oncol Biol Phys 45:253-254

8. Bleiberg H, Conroy T, Paillot B, Lacave AJ, Blijham G, Jacob JH, Bedenne L, Namer M, De Besi P, Gay F, Collette L, Sahmoud T (1997) Randomised phase II study of cisplatin and 5-fluorouracil (5-FU) versus cisplatin alone in advanced squamous cell oesophageal cancer. Eur J Cancer 33:1216-1220

9. Carraro S, Roca EL, Cartelli C, Rafailovici L, Castillo Odena S, Wasserman E, Gualdrini U, Huertas E, Barugel M, Ballarino G, Rodriguez MC, Masciangioli G (2002) Radiochemotherapy with short daily infusion of low-dose oxaliplatin, leucovorin, and 5-FU in T3-T4 unresectable rectal cancer: a phase II IATTGI study. Int J Radiat Oncol Biol Phys 54:397-402

10. Chiarion-Sileni V, Corti L, Ruol A, Innocente R, Boso C, Del Bianco P, Pigozzo J, Mazzarotto R, Tomassi O, Ancona E (2007) Phase II trial of docetaxel, cisplatin and fluorouracil followed by carboplatin and radiotherapy in locally advanced oesophageal cancer. Br J Cancer 96:432-438

11. Cividalli A, Ceciarelli F, Livdi E, Altavista P, Cruciani G, Marchetti P, Danesi DT (2002) Radiosensitization by oxaliplatin in a mouse adenocarcinoma: influence of treatment schedule. Int J Radiat Oncol Biol Phys 52:1092-1098

12. Cooper JS, Guo MD, Herskovic A, Macdonald JS, Martenson JA Jr, Al-Sarraf M, Byhardt R, Russell AH, Beitler JJ, Spencer S, Asbell SO, Graham MV, Leichman LL (1999) Chemoradiotherapy of locally advanced esophageal cancer: long-term follow-up of a prospective randomized trial (RTOG 85-01) Radiation Therapy Oncology Group. JAMA 281:1623-1627

13. Cronin-Fenton DP, Sharp L, Carsin AE, Comber H (2007) Patterns of care and effects on mortality for cancers of the oesophagus and gastric cardia: a population-based study. Eur J Cancer 43:565-575

14. Cunningham D, Starling N, Rao S, Iveson T, Nicolson M, Coxon F, Middleton G, Daniel F, Oates J, Norman AR (2008) Capecitabine and oxaliplatin for advanced esophagogastric cancer. N Engl J Med 358:36-46

15. de Gramont A, Figer A, Seymour M, Homerin M, Hmissi A, Cassidy J, Boni C, Cortes-Funes H, Cervantes A, Freyer G, Papamichael D, Le Bail N, Louvet C, Hendler D, de Braud F, Wilson C, Morvan F, Bonetti A (2000) Leucovorin and fluorouracil with or without oxaliplatin as first-line treatment in advanced colorectal cancer. J Clin Oncol 18:2938-2947

16. Extra JM, Espie M, Calvo F, Ferme C, Mignot L, Marty M (1990) Phase I study of oxaliplatin in patients with advanced cancer. Cancer Chemother Pharmacol 25:299-303

17. Freyer G, Bossard N, Romestaing P, Mornex F, Chapet O, TrilletLenoir V, Gerard JP (2001) Addition of oxaliplatin to continuous fluorouracil, l-folinic acid, and concomitant radiotherapy in rectal cancer: the Lyon R 97-03 phase I trial. J Clin Oncol 19:2433-2438

18. Gebski V, Burmeister B, Smithers BM, Foo K, Zalcberg J, Simes J (2007) Survival benefits from neoadjuvant chemoradiotherapy or chemotherapy in oesophageal carcinoma: a meta-analysis. Lancet Oncol 8:226-234 
19. Geh JI (2002) The use of chemoradiotherapy in oesophageal cancer. Eur J Cancer 38:300-313

20. Greene FL, Page DL, Fleming ID et al (eds) (2002) American Joint Committee on Cancer Staging Manual, 6th edn. Springer, Philadelphia

21. Herskovic A, Martz K, al-Sarraf M, Leichman L, Brindle J, Vaitkevicius V, Cooper J, Byhardt R, Davis L, Emami B (1992) Combined chemotherapy and radiotherapy compared with radiotherapy alone in patients with cancer of the esophagus. $\mathrm{N}$ Engl $\mathrm{J}$ Med 326:1593-1598

22. Hryniuk WM, Goodyear M (1990) The calculation of received dose intensity. J Clin Oncol 8:1935-1937

23. Jatoi A, Murphy BR, Foster NR, Nikcevich DA, Alberts SR, Knost JA, Fitch TR, Rowland KM Jr (2006) Oxaliplatin and capecitabine in patients with metastatic adenocarcinoma of the esophagus, gastroesophageal junction and gastric cardia: a phase II study from the North Central Cancer Treatment Group. Ann Oncol 17:29-34

24. Kelsen DP, Ginsberg R, Pajak TF, Sheahan DG, Gunderson L, Mortimer J, Estes N, Haller DG, Ajani J, Kocha W, Minsky BD, Roth JA (1998) Chemotherapy followed by surgery compared with surgery alone for localized esophageal cancer. N Engl J Med 339:1979-1984

25. Khushalani NI, Leichman CG, Proulx G, Nava H, Bodnar L, Klippenstein D, Litwin A, Smith J, Nava E, Pendyala L, Smith P, Greco W, Berdzik J, Douglass H, Leichman L (2002) Oxaliplatin in combination with protracted-infusion fluorouracil and radiation: report of a clinical trial for patients with esophageal cancer. J Clin Oncol 20:2844-2850

26. Knyrim K, Wagner HJ, Bethge N, Keymling M, Vakil N (1993) A controlled trial of an expansile metal stent for palliation of esophageal obstruction due to inoperable cancer. $\mathrm{N}$ Engl J Med 329:1302-1307

27. Malaisrie SC, Hofstetter WL, Correa AM, Ajani JA, Komaki RR, Rice DC, Vaporciyan AA, Walsh GL, Roth JA, Wu TT, Swisher SG (2006) The addition of induction chemotherapy to preoperative, concurrent chemoradiotherapy improves tumor response in patients with esophageal adenocarcinoma. Cancer 107:967-974

28. Mariette C, Finzi L, Piessen G, Van Seuningen I, Triboulet JP (2005) Esophageal carcinoma: prognostic differences between squamous cell carcinoma and adenocarcinoma. World J Surg 29:39-45

29. Mariette C, Triboulet JP (2006) Should resectable esophageal cancer be resected? Ann Surg Oncol 13:447-449

30. Mauer AM, Kraut EH, Krauss SA, Ansari RH, Kasza K, Szeto L, Vokes EE (2005) Phase II trial of oxaliplatin, leucovorin and fluorouracil in patients with advanced carcinoma of the esophagus. Ann Oncol 16:1320-1325

31. Maurel J, Cervantes A, Conill C, Salazar R, Martin-Richard M, Pera M, Manzano H, Chirivella I, Gallego R, Marfa X (2005)
Phase I trial of oxaliplatin in combination with cisplatin, protected-infusion fluorouracil, and radiotherapy in advanced esophageal and gastroesophageal carcinoma. Int J Radiat Oncol Biol Phys 62:91-96

32. O'Connor BM, Chadha MK, Pande A, Lombardo JC, Nwogu CE, Nava HR, Yang G, Javle MM (2007) Concurrent oxaliplatin, 5fluorouracil, and radiotherapy in the treatment of locally advanced esophageal carcinoma. Cancer J 13:119-124

33. Polee MB, Hop WC, Kok TC, Eskens FA, van der Burg ME, Splinter TA, Siersema PD, Tilanus HW, Stoter G, van der Gaast A (2003) Prognostic factors for survival in patients with advanced oesophageal cancer treated with cisplatin-based combination chemotherapy. Br J Cancer 89:2045-2050

34. Rohatgi P, Swisher SG, Correa AM, Wu TT, Liao Z, Komaki R, Walsh GL, Vaporciyan AA, Rice DC, Roth JA, Ajani JA (2005) Characterization of pathologic complete response after preoperative chemoradiotherapy in carcinoma of the esophagus and outcome after pathologic complete response. Cancer 104:2365-2372

35. Siewert JR, Ott K (2007) Are squamous and adenocarcinomas of the esophagus the same disease? Semin Radiat Oncol 17:38-44

36. Siewert JR, Stein HJ, Feith M, Bruecher BL, Bartels H, Fink U (2001) Histologic tumor type is an independent prognostic parameter in esophageal cancer: lessons from more than 1, 000 consecutive resections at a single center in the Western world. Ann Surg 234:360-367 discussion 368-9

37. Stahl M, Stuschke M, Lehmann N, Meyer HJ, Walz MK, Seeber S, Klump B, Budach W, Teichmann R, Schmitt M, Schmitt G, Franke C, Wilke H (2005) Chemoradiation with and without surgery in patients with locally advanced squamous cell carcinoma of the esophagus. J Clin Oncol 23:2310-2317

38. Urba SG, Orringer MB, Turrisi A, Iannettoni M, Forastiere A Strawderman M (2001) Randomized trial of preoperative chemoradiation versus surgery alone in patients with locoregional esophageal carcinoma. J Clin Oncol 19:305-313

39. Viklund P, Lindblad M, Lu M, Ye W, Johansson J, Lagergren J (2006) Risk factors for complications after esophageal cancer resection: a prospective population-based study in Sweden. Ann Surg 243:204-211

40. Xiao ZF, Yang ZY, Miao YJ, Wang LH, Yin WB, Gu XZ, Zhang DC, Sun KL, Chen GY, He J (2005) Influence of number of metastatic lymph nodes on survival of curative resected thoracic esophageal cancer patients and value of radiotherapy: report of 549 cases. Int J Radiat Oncol Biol Phys 62:82-90

41. Zhang Z, Liao Z, Jin J, Ajani J, Chang JY, Jeter M, Guerrero T, Stevens CW, Swisher S, Ho L, Yao J, Allen P, Cox JD, Komaki R (2005) Dose-response relationship in locoregional control for patients with stage II-III esophageal cancer treated with concurrent chemotherapy and radiotherapy. Int J Radiat Oncol Biol Phys 61:656-664 